\title{
Understanding Work Historically: A reflection prompted by two recent studies of the fur trade
}

\author{
Robert C.H. Sweeny
}

Edith L. Burley. Servants of the Honourable Company: Work, Discipline and Conflict in the Hudson's Bay Company, 1770-1879. (Don Mills: Oxford University Press 1997).

Richard Somerset Mackie. Trading Beyond the Mountains: The British Fur Trade on the Pacific, 1793-1843. (Vancouver: UBC Press 1997).

THE FUR TRADE long occupied pride of place in the writing of Canadian history. For a generation Harold Innis's assertion, that the fur trade explains why Canada exists as a country, stood largely unquestioned. In the mid-1970s, this began to change as support grew for Stanley Ryerson's conflicting argument that industrialization preceded Confederation. Then, for more than a decade, labour, social, and women's history flourished as historians focused on the transformation of Canada in the 19 th century. No new disciplinary consensus emerged, however, and in recent years the gap between historians interested in these newer approaches and those who defend the liberal values of an older, largely political, historical narrative has developed into an open rift. So, in their radically different readings of the fur trade, these two new books do not represent a rencwed interest in an older field as much as they symbolize the politically contested terrain that is Canadian history.

Edith Burley's path-breaking study merits the Macdonald Prize. Servants of the Honourable Company is a stimulating and richly textured application of lessons learned in two decades of labour history. Her subject is the people who worked under contract as long-term employees of the Hudson's Bay Company when it actively exploited the interior of Rupert's. Land. Her historical argument is that changes in the Company's operations can be explained largely in terms of repeated attempts to resolve the twin problems of labour recruitment and work discipline.

Robert C.H. Sweeny, "Understanding Work Historically: A reflection prompted by two recent studies of the fur trade," Labour/Le Travail, 41 (Spring 1997), 243-52. 
Burley is highly critical of how we think about the fur trade. She argues that, under the influence of ethnic stereotypes, an uncritical acceptance of the view from the top has impeded any recognition, let alone understanding, of the role played by the Company's workers. If we are to understand properly the choices these people made and the constraints under which they lived, she argues, we must recognise the significance of their experience as servants, within a pre-industrial, paternalistic master/servant relationship.

In contrast, Richard Mackie draws on business history, historical geography, and selective insights from Innis to make Trading Beyond the Mountains a significant contribution to the emerging national meta-narrative. His subject is the Hudson's Bay Company and how, in the decades after. 1821, its officers successfully created a diversified trading company that dominated the coast from California to Alaska. His historical argument is that the visionary leadership and unrivalled capital resources of the Company combined to create "a healthy capitalism adapted to local conditions" (261) which defeated all competitors. How then are we to think of this singular achievement? For Mackie, although the spoils of this complete commercial victory of the British over American and Russian rivals would be lost in diplomatic negotiations, the history of what he presents as the first British Columbia owed more to a diversified Pacific rim trading of natural resources than it did to the fur trade. The parallels to the present could not be more clearly drawn.

There can be little doubt that for the readers of Labour/Le Travail, Burley's detailed and sympathetic reconstruction of early labour relations will be of greater interest than Mackie's tale of great businessmen in history. After all, labour historians are concerned with working people. In Burley's study the servants all have names and she never allows the reader to lose sight of their humanity. Whereas in Mackie's study only selected, most frequently British, officers of the Company are ever properly identified, while the workforce, mostly Canadiens but with a remarkable mix of indigenous peoples from Iroquois to Kanaka, remains anonymous. As this might suggest, Burley's study is based on an enormous amount of archival research, while Mackie's rests on a selective mining of the correspondence of leading officers. There is, however, a profound irony: not only is Mackie's study far more likely to be read by people outside the academy, he actually provides the reader with a better understanding of the changing nature of work.

To understand this ironic state of affairs context, theory, and method al] need to be discussed, but first a final word of introduction. Fifteen years ago, Richard Rice argued that the history of working people requires its own theory and method; bourgeois approaches and techniques are not only inappropriate, but antithetical to the interests of working people. ${ }^{1}$ These two books, on similar topics but with radically differing approaches, offer the opportunity to assess how far we have come in meeting Rice's challenge.

'Richard Rice, "Sailortown: Theory and Method in ordinary people's History," Acadiensis (Fall 1983), 154-68. 
The authors' opposing arguments require differing structures. In her provocative introduction, Burley argues that historians have paid insufficient attention to the fur trade as a business. Since the Hudson's Bay Company was a highly profitable firm, with a long experience in pre-industrial labour relations, she structures her study into two parts. The first consists of a brief history of the trade and a historical sketch of labour recruitment strategies. Explicitly couched in the language of the managing committee in London, this "view from the top" is then contrasted with a "view from the bottom." A qualitative assessment of a quantitative analysis of disciplinary problems introduces extended discussions of first individual and then collective acts of insubordination and resistance.

None of the actions detailed by Burley are mentioned by Mackie, for whom the Company's internal labour relations have no historical importance, because the challenge facing officers of the Company was how to adapt their business to local conditions. The key to his structure of argument lies in an 1831 observation by Duncan Finlayson: "By its overpowering abundance all nature here demands attention." (69) For Mackie, the context necessary to understand the Company's actions is the different eco-systems of the Pacific coast. So a tour of the opportunities of the South, the Northwest and the Pacific rim respectively lead into a discussion of how the Company built on these to diversify beyond "the mere traffic in peltries." Local success and initiative were, however, compromised by external factors. A decline in European markets for fur coincided with increased American pressure to occupy the Oregon territory. The transfer of the Company's regional headquarters, from Fort Vancouver on the Columbia River to Victoria on Vancouver Island, is represented as an appropriate strategic adjustment to these changing conditions.

If, for Burley, the context is a Company whose actions are determined by an unchanging, but tension-ridden; pre-industrial master/servant relationship, for Mackie, the context is one of the most remarkable series of eco-systems in the world. Clearly, Mackie enjoys a dramatic advantage. It is his treatment of indigenous people, however, that sustains the narrative power of his work.

After Mackie has completed his story, at the very end of the book, is a chapter entitled "The Native Foundation of Trade and Labour." So it might appear that he considered indigenous peoples only as an afterthought, but such was not at all the case. For Mackie, native people were important because they were an essential and integral part of the environment. They were introduced and discussed extensively in the fourth chapter: "Nature here demands attention." Such an apparently holistic treatment is in fact racist: nature subsumes natives, while officers of the Company command it. Consistent with 19th century practices of reducing indigenous culture to artifacts adorning natural history museums, Mackie's approach speaks to very strongly entrenched perceptions within white culture. It resonates with the imperialism of Joseph Conrad's exploration of another 19th century European trading company in Heart of Darkness. For like Conrad's narrator, Mackie treats questions 
of morality and civilization as questions for white officers. His definition of the context eliminates any need to discuss the moral and ethical implications of the Company's role in the centuries long European invasion of the Americas, while at the same time setting up the central moral dilemma in this chapter: the native practice of owning slaves spreads to the Company's employees and the officers fail to act.

So sadly, we are left with a paradox. A work which integrates racist and imperialist values is very likely to be more widely accepted, indeed popular, than a study consciously designed to demonstrate human agency in action. Why? I can think of three possible reasons: the mythology specific to staple trades; the nature of narrative structure; and the importance of change in history.

For hundreds of years both the cod fishery and the fur trade were important. They occupy a place in the popular understanding of early Canadian history, however, that completely overshadows all the other many and varied activities people did in this part of the world from the late 16 th to the early 19 th centuries. From his "resolute" fur traders on the opening page to his "fur trade visionaries" of the concluding paragraphs, Mackie skilfully manipulates this Canadian pantheon. Burley has set herself a much more difficult task. She directly and I think successfully challenges the very idea of a singular "fur trade society" by insisting on the divisive nature of class. Ultimately, however, she fails to break free from the mythology, because her exclusive focus on the intemal dynamics of master/servant relations does not allow the servants to have a life. I understand her problem all too well, because for years I made precisely the same error when thinking about the relationship between merchants and people working in the cod fishery. An empowering alternative history of people working in staple trades would recognize that they did far more with their lives than catch fish or trade furs.

Narrative structures in history generally work by building on existing normative values and beliefs. A story about a different time and place appears to make sense to us in the present because it conforms to the way we have been taught to look at the world and we look at the world in this way because it confirms our understanding of what is sensible. This normal basis sustains bourgeois historical narratives and undermines alternative ways of seeing the past, because in advanced capitatist countries hegemonic norms are almost invariably individualist and patriarchal and very frequently racist. To break this cycle, we have to tell our histories in such a way that they effectively challenge how our audience sees the present. The way we define historical context can be vitally important in this task. By highlighting how coherently different and changing a past was, context can redefine what we understand as sensible. On numerous specific points, particularly on ethnicity, Burley achieves precisely this subversive end. Unfortunately her definition of context, with its insistence on the unchanging nature of her key master/servant relationship, ultimately undermines this achievement. 
Both authors present their essential context as unchanging. But history is the explanation of change over time, so if the context does not change then key aspects of the resulting narrative are outside history. For bourgeois historical narratives this denial of change does not pose a problem because historical agency is conceived as the exclusive prerogative of a minority, one which is usually white, male, and wealthy. By defining so narrowly who has the ability to change the world, most people can be safely relegated to a changeless context without doing any serious damage to the story-line. For progressive scholarship, however, to deny change is self-defeating. It forecloses on the possibility of a genuine living dialogue between past and present.

It is possible that a historical relationship changes so slowly that over the short-term it appears to be changeless. This appearance is, however, an illusion. To make sense of continuously changing reality we may impose order by thinking of processes as if they were fixed structures; but change remains the only constant. In bourgeois historical theory and method denial of change and illusions of order are both important. They have justified repeated declarations that we have reached the end of history and they are regularly invoked to legitimize as "natural" a wide variety of socially constructed constraints and inequalities. For socialist historians, however, it is only through the struggle to overcome these constraints and end these inequalities that a truly human history may begin. In this struggle for a qualitatively different and better world, understanding the nature of change in the past can reveal to us important, historically-grounded, theoretical lessons. The labour theory of value offers an instructive case in point.

Labour creates value and the roots of social inequality are to be found in the differing ways people have devised of appropriating value. The history of this dual insight into the basis of wealth and class structure is quite recent. Only hinted at by Adam Smith, David Ricardo clearly stated the labour theory of value in 1817. By the mid-1820s, organic intellectuals of the English working class had developed the social implications of this economic theory into a critique of capital. So both components were widely accepted before Karl Marx and Frederick Engels started to work together in the mid-1840s. In the wake of the defeat of 1848 , a long-time officer of the Honourable East India Company, John Stuart Mill, redirected economic theory away from the labour theory of value. Building on his laissez-faire liberalism, W.S. Jevons and then Alfred Marshall would complete the task by eliminating from bourgeois economic theory any serious consideration of the constituent elements of capitalism: only incremental changes, at the margin of the unquestioned structure, merit attention.

So for a relatively brief period a new understanding of the socio-economic significance of work was the basis for an intellectual consensus in Great Britain. This new consensus challenged older ways of thinking. The premises of both the mercantilists, who believed that there was a fixed amount of wealth in the world, and the physiocrats, who thought that land was the basis of all wealth, were rejected. 
This remarkable period of intellectual ferment in Great Britain was part of what Marx would later describe as the maturation of capitalism, but 20 th century textbooks have reduced to the Industrial Revolution. It was also the period which is the primary focus for both Burley and Mackie.

According to Burley, in the 18 th century the Company's primary concern was to maintain 17th century wage levels. She argues that a complex process of retrenchment and reorganization of the Company, between 1806 and 1814, rather than the merger of 1821 , was the defining moment for the firm in her period. She believes that the failure which met the attempt to introduce piece work combines with the continued paternalism of the officers to prove that the master/servant relationship survived retrenchment and reorganization intact. Indeed, she suggests that these changes took place in order to deal with problems that potentially threatened the continued viability of the master/servant relationship itself. At a loss to explain structurally the Company's acceptance of wage increases ranging from 300 to 400 per cent, she falls back on a market-led explanation, unrelated to the dynamics of the master/servant relationship. Perhaps cognizant of the weakness of her argument here, she stresses the increasing difficulties the Company faced in labour recruitment.

The relationship between masters and servants could not and did not emerge unscathed from the fundamental realignment of social forces resulting from the maturation of capitalism in Great Britain. Burley is correct in situating the origins of this legal relationship in the late middle ages and in stressing its importance in the early modern world. The economic logic of the master/servant relationship recognized the significance of market forces in establishing wage levels. Indeed, it was to control these levels that the statutes were first enacted. It did not recognize, however, that labour created value. Nor could it, for the master/servant relationship was premised on a social order in which value was conceived in largely non-economic terms and, perhaps more importantly, the appropriation of value by dominant social classes took place primarily outside the productive process itself. When both the premise and the economic reality changed, the Company would find its legal rights as master recognized but extremely difficult to enforce. Nor could this have come as any great surprise, for the years of retrenchment and reorganization introduced detailed accounting procedures for each post, which permitted for the first time an effective cost/benefit analysis of servants' labour, freeing wages from the traditional limits, and introduced profit sharing for the officers. Paternalism would continue, but now it served a new relationship characteristic of a new age.

In contrast, unencumbered by an unchanging pre-industrial paternalist relationship, Mackie admiringly, albeit unwittingly, chronicles how officers applied the new political economy to generate new sources of wealth for the Company. Take, for instance, John McLoughlin in May of 1834 commenting on the use of Kwantlen farm labourers in Langley Plain: "I approve very much of your Employing Indians and paying them with the produce of your farm as this Labour costs 
you nothing." (297) Or, even more insidiously, the way in the Company speculatively devalued the haiqua (the principal indigenous currency) and established Hudson's Bay blankets as the primary circulating medium, thereby ensuring the maximum transfer to the Company's books of value generated by labour within indigenous communities.

I do not mean to suggest by these examples that the officers of the company eagerly studied their Ricardo like some early George Soros of the Pacific rim. Does Mike Harris study Hayek or Friedman? No, these ideas, like the neo-liberalism of today, represented an intellectual consensus about how political economy works, an issue of central concem for the Company's officers in both North America and London. Indeed, as Mackie shows in his chapter on the crisis the fur trade faced by the 1840s, the Company developed a completely new strategy based on accurate profit and loss figures by productive activity. As this reminds us, capitalism, "healthy" or otherwise, is based not on patemalism but on the direct appropriation of value created by labour.

In a passage evocative of E.P. Thompson's famous call to rescue working people from the "enormous condescension of posterity," Burley concludes that "the disobedience and discontentment" of Company servants "are as important a part of HBC history as the voyages of David Thompson, the imperium of George Simpson, and the plans and pronounceiments of the London committee." (248) I agree and this important study shows why these factors should loom large in any history of the for trade. I think, however, it was the servants' work which made them historically more important than their officers. Work figures much more prominently in Burley's title than it does in the text, because of a relationship between historiographical traditions and methodological choices.

Labour history is somewhat of a misnomer, for relatively few labour historians are concerned with work. The social relations of workplace, family and community, the development of working class institutional and cultural life, the politics of reform and revolution, these are the primary and legitimate concerns of labour historians. So in focusing on the dynamics of pre-industrial labour relations, rather than on what people working for the Company actually did most of the time, Burley is following a well-established historiographical tradition.

Now, people talk and think about their work much more than this academic tradition would suggest. And then, work related problems and stories, or simply the satisfaction of a job well-done, were much more likely to bave been the recurring topics of conversation among servants of the Company than either disobedience or discontentment and for good reason. Their labour created value and they would generally have been proud of what they had achieved. As E.P. Thompson noted more than forty years ago: "Imaginative and intellectual faculties are [...] implicit in the creative act of labour which makes man man.," Moreover ${ }^{2}$ E.P. Thompson, "Socialist Humanism," New Reasoner, 1 (1957), 131. Cited by Ellen Meiksins Wood, "The Debate on Base and Superstructure," in Havey J. Kaye and Keith McClelland, eds., E.P. Thompson, Critical Perspectives (Philadelphia 1990), 139. 
in their work, servants of the Company frequently had to overcome very difficult natural conditions and engage in challenging cross-cultural exchanges, a combination which must have given some reason for sober second thought and others the need for a swig. These thoughts, ideas, perceptions, actions, and reactions were constitutive components of the servants' culture. Cultures are about both shared experiences and the drawing of exclusive, yet flexible, boundaries. So if one fails to examine work seriously, then the nature of the relationship between servants and their officers cannot be understood historically.

This failing is not that of an individual scholar, but rather of a whole historiographical tradition. In labour history, we consistently make methodological choices inappropriate to the history of working people. We combine a declared and genuine sympathy for working people with the highest and most recent professional standards. All the sympathy we can muster, however, is simply insufficient to overcome the bourgeois character of professionally accepted approaches and tools of inquiry. We need a radically different historical theory and method. Imagine what the state of women's history would be if feminist scholars refused to engage critically the theoretical and practical implications of gender on the way they do history. For labour history, why should work be any different?

The archives of the Hudson's Bay Company are so large that a selective approach is mandatory. Sometimes, as in the case of Mackie, the methodological choices are neither particularly well thought-out, nor subsequently verified. Mackie assumed a limited number of officers made history and so he selectively mined some of their correspondence for material to support his narrative. As Burley repeatedly shows, however, these officers' visionary letters were often nearsighted, self-serving, and frequently simply wrong. To be fair, Mackie has no need of a discourse of proof, because "healthy capitalism adapted to local conditions" is an ideological statement, not a historical hypothesis.

Burley's selective approach to the archives was qualitatively different. Although the volume of materials she examined is awesome, Burley designed her study around the results of a systematic sampling. She examined all the available material for each tenth outfit (a year's operations starting on 1 June) for an entire century. She recorded each and every example of misbehaviour on the part of servants and officers. She then analyzed the data over time both in terms of forms and types of misbehaviour. She subjected this quantitative analysis to a reasoned qualitative assessment. Since such a sampling procedure involves value judgements, she openly and clearly sets out the problems she encountered in classifying the data. She then discussed patterns of continuity and change in individual and collective acts of insubordination and resistance. As I hope $I$ have made clear, Burley's research meets the highest professional standards of bourgeois historical theory and method.

The problem is twofold: the method used to organize the material and the conceptual approach to the sources themselves. By organizing the material in terms 
of specific, recorded actions or incidents of misbehaviour, Burley necessarily abstracted these events from their historically specific context, which would have been in many, if not most cases, a context of work.

Nor is this problem resolved by the subsequent separate analyses over time of individual and then collective forms and types of insubordination and resistance. For as their very separateness shows, these analyses only appear to be historical; they are in fact diachronic: an examination of selected variables over time. A variable in diachronic analysis is like a photograph: once taken you cannot put it back. Once created all the declared sympathy for the subject will be insufficient to reinsert a selected variable back into its historical context, because the act of selection strips it of its historical specificity. In short, Burley's initial methodological choices meant that work could not be a central theme of the study.

To be fair, this marginalization of work was less essential than it might first appear. Burley presumed a status-based master/servant relationship, wherein al] situations, not just those involving work, would be master/servant relations. This presumption needed to be tested; for if the company was no longer thinking of itself as a master and its employees as servants, or if the employees no longer considered themselves as servants and their officers as representatives of the master, then behind any appearance of continuity would lie fundamental change.

Historical changes of this magnitude are difficult to hide. In order not to see them, one must follow strictly the highest standards of our profession and consider historical sources to be inert: repositories of discursive and quantitative data to be mined with our latest techniques and sensitive to the most recent intellectual approaches. Revolutionary historical theory and method involves a radically different understanding of the nature and potential role of historical sources. Each source is ontologically distinct, with its own internal logic, that bears witness to the historical specificity of its creation. Seen in this way historical research involves a continuous dialogue between an historian in the present and distinct sources speaking to us from the past. This complex, multi-layered conversation can only be possible if we respect the epistemological autonomy of each source. The historical logic of each source, why it exists, has to be clearly posited by the historian. Furthermore, this logic must be respected when assessing not only how, but if, evidence from a particular source may enter into a discourse of proof.

Applying these principles to a historical study of working for the Company would suggest that the documentary revolution, which attended the reorganization and restructuring of the Company, was a focal point of change. These new methods of accounting and recording work spoke to the complexity and fundamental nature of change. For example, the change in the unit of account, from a made beaver to a pound sterling, meant for the first time the Company could assess all costs in terms of labour, surely not an insignificant consideration in the maturation of capitalist social relations. Furthermore, these principles would allow for an historical analysis of insubordination and resistance, because by respecting the specificity 
of the source, how and why we know about a particular action or event guides both researcher and reader.

In the decade and a half since Rice wrote his essay, labour history has progressed. In the best of the recent work, as Servants of the Honourable Company shows, many of the difficult technical problems Rice highlighted have been resolved. The fundamental problem of the class-based nature of historical theory and method, however, remains and the ironic paradox that has been central to this review should be understood in those terms. In advanced capitalist societies, academic approaches to history share a common class basis: historical theory and method serve the interests of the bourgeoisie. As Trading Beyond the Mountains reminds us, such history can be highly political, for at stake are the fundamental issues of our time. There is an altemative. But it requires more than sympathetic research. It involves qualitatively different historical theory and method, conceived to serve the interests of working people. Only then may we begin to hear clearly the long muffled voices of those whose labour created value. They have so much to teach us and we so much to learn. 